\title{
Training and Development Model for Higher Education Institution in the Context of Lao P.D.R
}

\author{
Assoc. Prof. Dr. Shahren Ahmad Zaidi Adruce \\ Director of Borneo Studies Institute, University Malaysia Sarawak (UNIMAS), \\ 94300 Kota Samarahan, Sarawak, Malaysia
}

Dr. Zaimuariffudin Shukri Nordin

Senior Lecturer, Faculty of Cognitive Sciences and Human Development

University Malaysia Sarawak (UNIMAS),

94300 Koata Samarahan, Sarawak. Malaysia

\begin{abstract}
Khanthaly Sae Phimmasenh (Corresponding Author)
Ph. D Researcher, Faculty of Cognitive Sciences and Human Development, University Malaysia Sarawak (UNIMAS), Malaysia, or

Champasak University, Lao P.D.R

Tel: 60-178-450-811Ｅ-mail: khphimmasenh@gmail.com
\end{abstract}

Received: May 29, 2017 Accepted: June 27, 2017 Published: July 5, 2017

doi:10.5296/ijld.v7i3.11304 URL: https://doi.org/10.5296/ijld.v7i3.11304

\begin{abstract}
In the constantly changing environment, organizations have to find ways to maintain their competitive advantage. Training and development model for higher learning institution is one of the ways in which organization can find its competitive advantage because university lecturers being trained have more diverse set of knowledge and skills that will help to support the organization growth. This research tries to find out the suitable model for training of personnel. Initially, a detailed review about challenges to higher education in the context of Lao P.D.R in this matter is presented and then the research introduces a framework of a proposed model of personnel training in a higher learning institution.
\end{abstract}

Keywords: Training, development model, higher education institution, training strength, training weaknesses, lifelong learning 


\section{Introduction}

The Lao government's goals are to elevate the country from being one of the least developed countries in the world by keeping the rate of its economic growth at a moderate and stable speed. It is important to note that close attention is paid to education in order to develop human resources in the country. In the government's strategy on educational development it is mainly focusing on quality improvement for developing national human resources to meet the needs of the country's socio-economic development. This study purports to explore the training and development program in higher learning institutions. This study attempts to assess the university lecturers' perception of the strengths of the training program, the weaknesses of the training program, how training program benefits the university lecturers, how training program benefits higher learning institutions, the training activities organized by the institution to support training and development program, critical components of training program in a higher learning institution as well as the suitable training model for higher learning institutions. Training and development play an essential role in the effectiveness of organizations and to the reviews of human being at workplace. Training has implications for productiveness, healthy and protection at work and personal development. The success of training and development programs in an organization depends on the effective implementation of its training and development plan. The training and development plan of a particular training and development program in an organization must be informed by a specific training and development model. This is done so that training is managed effectively and efficiently, in order that the transfer of training can be optimized, and the set objectives achieved. Therefore, this study is conducted to explore training and development program for institutions of higher education in Lao P.D.R to implement an effective training program, having the right training model is crucial to attain organization's mission and success.

\subsection{Problem Statement}

In early 1990, the lack of attention to tertiary education was that opportunity given to many students to study in Soviet Bloc countries. The main reason for this was that there were very few tertiary educational institutions in Laos and the country faced the several lack of funds, resources and qualified personnel equipped for training in its higher education institutions. During this period, most students were sent to study in former socialist countries as mentioned such as Vietnam, the Soviet Union, Poland, Hungary, Bulgaria, East Germany, etc. After the collapse of the Soviet Union (1991), Lao students have been sent to some Asian countries, i.e., Vietnam, China, Thailand, India, the Philippines, Malaysia, Singapore, Japan, and Australia.

There were several studies conducted to explore the training and development as it helped employees and organizations to develop their performances and benefits, but most were done outside Laos. Therefore, there is a need to discover training model that suitable for Lao people. On the other hand, this research addressed this gap through the following the research questions; what are training strengths in a higher learning institution, what are training weaknesses in a higher learning institution, and then what is a suitable training model for university lecturers in a higher learning institution. 


\section{Higher Learning Institutions in the Context of Lao P.D.R}

Higher learning institution in Laos began officially in 1958 with the Royal Institute of Law and Administration in Vientiane. After that, the National Institute of Pedagogy of Vientiane (NIPV) was found in 1964 to train the primary and lower secondary school teachers. The Pathet Lao government in Huaphan Province redesigned the Normal School of Viengsay to higher education status with the establishment of a section for the training of secondary school educators in 1974. After the foundation of the Democratic People's Republic of Laos in 1975, the NIPV and the Viengsay Normal School were included together into the Higher Institute of Pedagogy of Vientiane (HIPV). The HIPV had two branchs arranged in Luangprabang and in Savanakhet Provice. In addition, the Faculty of Medicine of the past Royal School of Medicine in Vientiane was reestablished as the Higher School of Medical Sciences in 1975 (Can, 1991).

The National Polytechnic Institute (NPI) was built up in Vientiane in 1984. This institution had four assets: (1) Faculty of Fundamental Sciences; (2) Faculty of Civil Engineering; (3) Faculty of Mechanical Engineering; and (4) Faculty of Electrical Engineering. The course of study was 5 years. A couple understudies went to a 1-year preparatory course at the Institute before entering propelled training courses (Ogawa, 2008).

Bourdet (2001) specified that Higher education was less of a priority while, Lao Government took over in 1975. Higher education remained strictly limited until the early 1990. A factor that contributed greatly to the lack of attention to higher education was the opportunity given to many students to study in the Soviet Bloc countries. During the first one and a half decades of the Lao People's Democratic Republic, mostly Lao students were sent for training in Vietnam, the Soviet Union or Eastern Europe. In the late 1980s the Lao government launched an ambitious policy of reforms named the New Economic Mechanism. This led the government to create a Steering Committee on Human Resource Development in 1994 with the objective of planning and strengthening higher education in Laos.

The Government of Lao PDR reformed the public and private higher education system with the top Minister's Decree on Private Higher Education in 1995 and the Decree of the Higher Education Curriculum (National Standard) in 2001. The Decree also amalgamates ten higher learning institutions under the structure of the NUOL including the College of Law. The purposes of the reforms were twofold: (1) to meet the social and economic needs of the country by liberalization and privatization of higher education; and (2) to make them capable of exploiting and mobilizing the modernization process. The Educational Law was promulgated in April 2000, and article 3 of the law states: "All Lao citizens (non discrimination of ethnic group, race, religion, sex and social conditions), have the right to education" (Constitution of Lao PDR 1991: 1).

Announce No 50/PM dated 09/06/1995 states that the NUOL is a piece of the MOES with obligation regarding advanced education which is the principal advanced education establishment in Lao PDR. Up to now, there were four noteworthy state funded universities in Lao P.D.R that under Higher Education Department, Ministry of Education and Sports, each one still lacks of experience, personnel and other conditions to motivate the process of 
learning and teaching effectively. In addition, the educational research is not conducted widely. National University of Laos is the first higher education institution that was established in 1996. Champasak University was established in 2002, Suphanouvong University was established in 2003 and Savannakhet University was established in 2009. Although, each university has developed gradually, they still need to be developing in order to make good condition to improve the knowledgeable, competent staff and to have a professional skill into the region and international cooperation.

Sikhamtath (2000) indicated the challenges in the new millennium for higher education. This paper covers in brief, major events in economic development in the Lao PDR since 1975 and associated developments in education over that period. The National Education Development Plan (1996-2000) identifies a number of general directions and specific targets for Lao education. Essentially the Plan calls for: compulsory education by 2000 ; expansion at all levels of education; higher efficiency in primary and secondary education through a reduction in the number of dropouts and repeaters; a range of organisational and curriculum changes in teacher education; literacy training with an emphasis on skills training; curriculum reform in vocational education; more effective financial management and use of budgets; management improvement at each level of education and expansion of the private education sector. The Plan stated that the priority concern is for teacher development, curriculum reform, and delivery of increased educational opportunities to educationally under-serviced areas. There are five programs for the 1996-2000 Plan, (1) General Education Development; (2) Teacher Training and Development; (3) Non-Formal Education Development; (4) Vocational, Technical and Higher Education Development; and (5) Administration and Management Development.

The Education and Sports Sector in Lao PDR is appropriately structured and resourced to create opportunity for all Lao citizens to have equitable access to quality education and sports and to benefit from socio-economic development in order for the Lao PDR to be eligible to graduate from least developed country status by 2020. Moreover, by 2030 all Lao population equally and equitably have access to quality education in order to become good citizens, disciplined, healthy, knowledgeable, highly-skilled with professionalism in order to sustainably develop the country, to align and be compatible with the region and the world (MOES, 2015).

The Government of the Lao PDR places education and sports development, as well as human resources development, as an important key in national socio-economic development to enable the Lao PDR to graduate from the ranks of least developed countries by 2020 and move to industrialization and modernity. Both the 8th National Socio-Economic Development Plan (NSEDP) and the 9th Lao People's Revolutionary Party Congress emphasize the pivotal role that education must play. The Congress highlighted the need for four "breakthrough" steps in pursuit of the renovation policy and future national development, including: (1) Advancements in ideology, (2) Human resources development, (3) Overcoming administrative barriers which impede business activities, and (4) Increasing efforts in poverty reduction.

Therefore, to meet the stated goals, the Lao Government has given priority to education, 
considering it a key element of the human resource development policy. The MOES however recognises that the quality of education does not meet the demands of society and the labour marketplace. Furthermore, the quality of education has not reached international standards. The reasons for this are in policy identified to be a need for more teaching staffs, a need for professional quality development among lecturers, a need for an improved training program for personnel, a need for improved university building and equipment, and a need for improved administration and management especially in higher learning institutions.

\section{Methodology}

\subsection{Research Design}

This research is qualitative study to explore the issue related to the training and development program in higher learning institutions. Through this case study, it provides the researcher with descriptive information on the understanding of respondents toward training and development program in higher learning institutions. Qualitative research puts emphases on understanding through looking closely on people's work, actions and records (Creswell, 1994). Qualitative research helps the researcher to understand the feelings, values, and perceptions that influence informant's behaviour. In this case, researcher will be able to access how the university lecturers perceive the strengths of training program, the weaknesses of the training program in higher learning institutions and then the suggestions on a suitable training model for higher learning institution. Apart from that, not much study has been conducted in this research field. Therefore, qualitative study can overcome the 'lack of literature resources' issue because when using this research approach, relevant data can be generated over time, through interactions with the informants.

\subsection{Population and Sampling}

Due to time constraint and lack of monetary resources, open-ended survey and interviews were conducted on 12 informants only, working as a lecturer whom was attended to the Pedagogical Training Program in various universities in Lao P.D.R. The research aimed to obtain 3 informants from each university, namely the National University of Laos, Champasack University, Suphanuvong University and Savannakhet University.

\subsection{Data Collection Instruments}

For qualitative research in this study, the researcher used two techniques to collect data answers the research objectives. The methods used throughout the study were open-ended survey and structured interview.

\subsection{Data Analysis}

Qualitative information may be analysed in numerous techniques. Content analysis is one of the maximum normally used techniques in analysing qualitative data to decide the presence of concepts within texts (the interview transcript or answer script) and their relationships. Content analysis is also useful in such a lot of exclusive methods. Accordinglly, Shahren, (2013), content analysis also assist the researcher to find out patent and theme inside texts; to decorate or maybe better, produce new theories as well as to come up with a version, proposition or hypothesis. basically, it includes the process of reading through the 
information scripts, developing codes, coding the data and drawing connections among fantastic pieces of data. To conduct a content analysis on a text, the text is coded, broken down, or decreased into smaller categories, in order that they come to be greater potential. This process is called coding. Those codes are then examined using one among content analysis's easy strategies, i.e., conceptual analysis or relational analysis. Conceptual analysis may be concept of as establishing the prevalence and frequency of requirements in a textual content, whereas, relational analysis may be perception of as inspecting the relationships among the ones concepts (Shahren, 2013). Further, data from the reports was exacted and later used to support each of the themes and categories suggested by adopted analytic framework and below are the narratives of themes and sub-themes of each category with profound or representative quotes embedded.

\section{Research Findings}

This section provides elaborations on the research findings obtained from the informants through open-ended questionnaire as well as a structured interview. Informants consist of the lecturers who participated in the Pedagogical Training Program in the National University of Laos, Souphanouvong University, Champasak University and Savannakhet University. There were 12 informants in this research and each of them is assigned various ranging from 1 to 12 . In this section, there also are four existing training programs such as the National University of Laos Program, Champasak University Program, Suphanuvong University Program and Savannakhet University Program. The three training programs were sponsored by Asian Development Bank (ADB), which aims to train the university lecturers in higher learning institutions on pedagogy areas under Strenghtening Higher Education Project (SHEP). Based on the data gathered from the informants, the greater details on strengths and weaknesses were discussed in subsections below:

\subsection{Strenghts of Training Program in Higher Learning Institutions}

Based on data gathered, there were six main strengths of training program in the higher learning institutions; increase capability, knowledge sharing, continuous learning, increase motivation, helps in addressing weaknesses and the lastly, training program helps to keep up with new technology.

For instant, informant 1 who is an expert in education management stated that the training program is very important for teacher educator's job because training helps the teacher educators to improve work capacity in the classroom management, teaching process as well knowledge subject. According to him:

"It is important to have training program in a higher learning institution to increase capacity of teaching staffs as well as teaching ability improvement in the classroom that why I was attended in the pedagogical training program"

Informant 10 also mentioned that training program also increases teacher educator capacity on the knowledge transfer. Training program is essential for knowledge transfer of teaching staffs because pedagogy training provided the methodology on how to conduct the teaching processes in the classroom and how to impart the knowledge to student effective. He said: 
"I think that Training is essential for all teacher educators to increase the work ability as a teaching methodology improvement on how to conduct the class with efficiently to ensure the knowledge transfer to students"

Lifelong learning is "the on-going, deliberate, and self-inspired" quest for information for either individual or expert reason as in a higher learning establishment, preparing program initiates deep rooted learning for instructor teachers. Long lasting learning will empower autonomous learning in the people to create themselves in an assortment of new sciences. As stipulated by informant 4 :

"Training is essential as it activates lifelong learning for teacher educator in the higher learning institution because it is the knowledge and skills improvement and to learn the new theory and new sciences".

Informant 3 highlighted that training program strengthen their knowledge and skills. For instance, informant 3 who is an expert in English language stated that participating in the training session helps him to understand about the teaching process, styles of lesson planning and the evaluation methods for the classroom. Therefore, training assists him to gain more knowledge and improve his teaching skills. According to him:

"Understand about step of teaching process, style of lesson plan and how to evaluate the teaching to improve better outcome so it helps to strengthen knowledge and skill for all teaching staff"

Informant 8 mentioned that training is very important as it helps to upgrade the pedagogical knowledge. He stated that:

"Training is very important because it helps to improve teaching skills, the process of teaching such as teaching plan, lesson plan, and knowledge transfer effectively and improve pedagogy knowledge for teaching staff in higher learning institution”.

Informant 9 mentioned that the technologies are constantly changing and so it is important for a teacher educator to develop to avoid being left behind. Therefore, it is important to conduct the ICT training for teacher educators to make sure that we keep in touch with the new technology development and up to date. He revealed that:

"Pedagogical and ICT training is very important for all university lecturers. It helps us keep in touch with the new technology development because the ICT is essential for working. Therefore, I really need to participate in this training program"

Additionally, informant 10 mentioned that training helps the lecturers understand the methodology in teaching-learning in the classroom. Informant 11 added that during a training session, the lecturers have the opportunity to share their experience and knowledge. Thus, knowledge sharing and attitudes with the other trainees, it helps to improve professional skills, techniques of teaching, and lesson planning.

\subsection{Weaknesses of Training Program in Higher Learning Institutions}

The informants were asked about their perception on the weaknesses of training program that they had participated in, as well as their perception on how to solve the problem found. There 
were four main weaknesses of training program, namely inadequate facilities, inappropriate trainer, budget constraint and inappropriate time as identified below:

Facilities play important roles in ensuring an effective training program session as stated by Informant 6 stated that:

"The information supporting is not enough. The presentation of trainer is not clear enough because of the signal of the internet is low speed"

As stipulated by informant 1 , the weaknesses of the training program are the period of training is too short and the materials also still limit. In addition, the explanation and answering the question of the trainer is not clear enough, as said by informant 3. On the other hand, informant 4 indicated that training cannot achieve the purpose and the goals of participants because of the trainer lacks of skills and experience. He noted that:

"Training cannot achieve the purpose and the goals of participants because of the trainer lacks of skills and experiences"

However, according to informant 2, 8 , and 9 mentioned that the budget for training program still limit to cover the necessary expenses for joining a training program, especially the allowance for participants still limits and the budget inability to sponsor or cover all staff to join in the training program. As stipulated by informant 9 :

"Many people in our institution still miss the chance to join in the training program because of the limit budget"

On the other hand, informant 12 indicated that in the action plan of the training program was not in accordance with the schedule. This's complicated for participants to follow. She noted that:

"The training action is not following the time schedule and also training program is conducted in a short period of time. Thus, it is complicated for participants to follow"

\section{Discussion}

Based on the research findings, there are six main strengths of training program in the higher learning institution; increase capability, knowledge sharing, continuous learning, increase motivation, helps in addressing weaknesses and the lastly, one of new finding in this field, training program helps to keep up with new technology. On the other hand, the research findings, there are six identified factors that may inhibit training program to implement smoothly. Two of those are inadequate facilities and budget constraint. The other two are new findings in this study, which are inappropriate trainer and in appropriate time. There are also the other barriers in training program found in other studies, but there are not revealed in this study, which are, lack of training needs identified (Mchanakutwa, 1999; Hamis, 2000) and not based on the training needs assessment or skills needed (Nyamwocha, 1996).

\subsection{Contribution of the Study}

This study highlights the importance of training and development contributes towards organization's success. Through this study, the organizations are able to develop the appropriate training model of higher educational institution and work together towards 


\section{Macrothink}

improving the practice in workplace.

Through this study, organizations are able to identify the factors that inhibit as well as encourage training among the staffs. Consequently, organizations can use the findings of this study to find the methods to establish training programs to build upon the available body of training program relating to job performance of practitioners.

The finding will serve as useful indicators for organizational leaders or ministry level as to what training model should be given when providing professional development programs to the university lecturers. One of the methods is through the implementation of the evolved recommendations in the employer. The guideline is practical to be included into the organizational policy due to the fact it's miles specially advanced based at the data obtained from the business enterprise itself as a proposed training model as below;

\subsection{Proposed Framework of Training Model for Higher Education Institution}

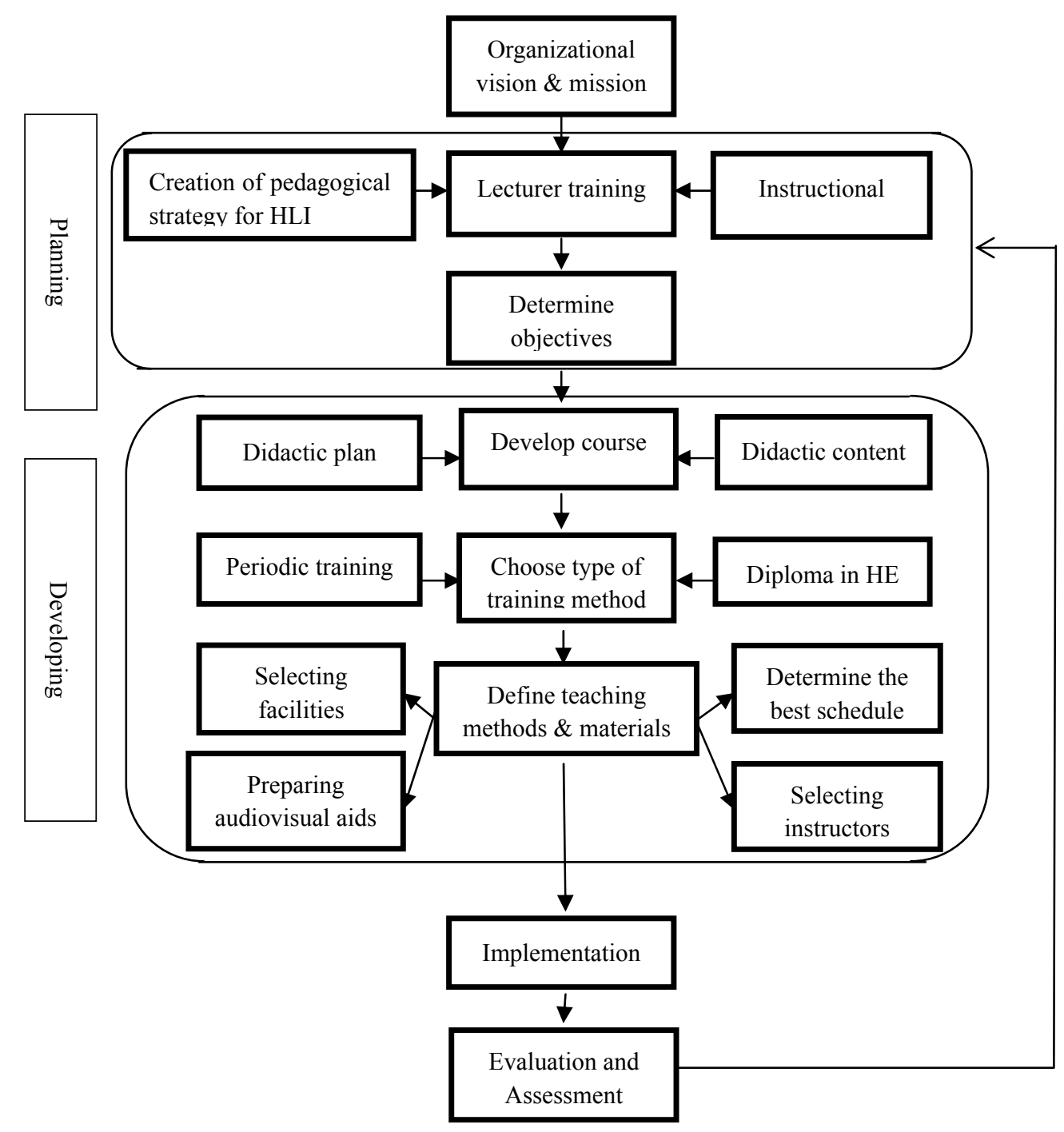

Figure 1. Shahren and Khanthaly Model 


\subsection{For Future Researchers}

The training and development program in a public higher learning institution may not be the same as the training and development program in a private higher learning institution. Hence, future researchers should try to investigate the differences by conducting their research in a private higher learning institution. Different outcomes may be generated as well, which further contributes to this particular research field.

Aside that, the future study may also focus on different aspects of training and development program such as on the process of training session or on the actual application of training and development program in the work processes. The future researchers may also conduct this very same study by using a different methodology, that is, by using a mixed method approach. Mixed method approach would be useful to find statistical connections among gathered data while enabling the researcher to explore the subject in greater depth.

\section{References}

Bourdet, Y. (2001). Strengthening Higher Education and Research in Laos. Department for Research Cooperation, SAREC, Sweden.

Can, L. T. (1991). Higher Education Reform in Vietnam, Laos, and Cambodia. Comparative Education Review, 35(1), 170-176. https://doi.org/10.1086/447001.

Constitution of Lao PDR (1991). Chapter 1: The Political Regime, Lao Government. Available: http://www.laoembassy.com/news/constitution/body.htm (January 25, 2008).

Ministry of Education and Sports (2000) The Education Strategic Vision Up To the Year 2020. Vientiane: MOES. Available: http://www.moe.gov.la (November 12, 2013).

Ministry of Education and Sport (2001) The Education Strategic Planning for 20 years (2001-2020), 10 years (2001-2010), and Five Year Development Plan for Education at the Fifth Plenary Session (2001-2005) (Part1 \& 2). Vientiane: MOES. Available: http://www. moe.gov.la/data/about_moes/12 (Febuary 22, 2014).

Ministry of Education and Sports (2003) Teacher Training Enhancement and Status of Teachers Project (TTEST). Vientiane: MOES.

Ministry of Education and Sports (2005) Education for All: National Plan of Action 2003-2015. Bangkok: UNESCO.

Ministry of Education and Sports (2006) Teacher Education Strategy Action Plan 2006-2015 and Action Plan 2006-2010 (Part 1 \& 2). Vientiane: MOES. Available: http://www. moe.gov.la/data/about_moes/12 (March 2, 2015).

Ministry of Education and Sport (MOES) (2006). Summary Note of Implementation of Education Development Plan 1998-2006. Vientiane: MOES. Available: http://www. moe.gov.la/decree/Decree1 (March 2, 2015).

Ministry of Education and Sports (2008). Education Reform Strategy 2006-2015. Vientiane: MOES. Available: http://www. moe.gov.la/data/about_moes/12 (March 2, 2015). 


\section{Macrothink}

International Journal of Learning and Development

ISSN 2164-4063 2017, Vol. 7, No. 3

Ministry of Education and Sports (2008). Decree on Organisation and Activities of Department of Higher Education.Vientiane: MOES. Available: http://www. moe.gov.la/decree/Decree 1 (March 2, 2015).

Ministry of Education and Sport (2008). Education Law.Vientiane: Lao Youth Printing Press.

Ministry of Education and Sports (2015). Education and Sports Sector Development Plan (2016-2020). Vientiane: MOES. Available: http://www. moe.gov.la/data/about_moes/12 (June $5,2017)$.

Ogawa, K. (2008). Higher Education in Lao People's Democratic Republic: Historical Perspective. Journal of International Cooperation Studies, 16(1), 105-129. https://doi.org/10.1007/978-1-349-12915-7_81.

Sikhamtath, M. (2000). Education in the Lao People's Democratic Republic: Challenge in the New Millennium. Journal of Southeast Asian Education, 1(1), 103-112. http://www.odci.gov/cia/publications/facebook/index.html.

UNESCO (2006). Higher Education in South-East Asia. Bangkok: UNESCO Asia and Pacific Regional Bureau for Education.

\section{Copyright Disclaimer}

Copyright for this article is retained by the author(s), with first publication rights granted to the journal.

This is an open-access article distributed under the terms and conditions of the Creative Commons Attribution license (http://creativecommons.org/licenses/by/4.0/). 